\title{
Pobreza, seguridade e assistência social: desafios da política social brasileira
}

\author{
Ana Paula Ornellas Mauriel \\ Universidade Federal Fluminense (UFF)
}

Pobreza, seguridade e assistência social: desafios da política social brasileira

Resumo: Este artigo apresenta resultados parciais de pesquisa sobre o combate à pobreza no Brasil. A principal contribuição do texto está em relacionar determinadas características dos programas de combate à pobreza a categorias teóricas que vem infuenciando o debate sobre política social no contexto contemporâneo. Atenção especial é dada à relação desses programas com a Política Nacional de Assistência Social. Para isso, o artigo parte da hipótese de que houve uma recondução da lógica que inspira a construção das políticas sociais, a partir de uma transformação do estatuto teórico da questão social e de suas formas de enfrentamento. Tal inflexão de sentido aparece no texto pela prioridade da pobreza enquanto categoria de análise, entendida como ausência de capacidades, configurando teórica e metodologicamente um foco individualista de pensar o social, cuja principal fonte teórica é o pensamento de Amartya Sen.

Palavras-chave: política social, seguridade social, assistência social, combate à pobreza.

\section{Poverty, Security and Social Assistance: Challenges of Brazilian Social Policy}

Abstract: This article presents partial results of a study about anti-poverty programs in Brazil. The main contribution of the text is that it relates certain characteristics of the anti poverty programs to theoretical categories that have influenced the debate about social policy in the contemporary context. Special attention is given to the relation of these programs with national social assistance policy. The article begins from the hypothesis that the logic that had inspired the construction of social policies was reconsidered, based on a transformation in the theoretical understanding of the social issue and of ways to confront it. This change appears in the texts in the priority given to poverty as a category of analysis, which is understood as an absence of capacities. This theoretically and methodologically configures an individualistic perspective on social issues, the principal theoretical source for which is the thinking of Amartya Sen.

Key words: social policy, social security, social assistance, fighting poverty. 


\section{Introdução}

Nas duas últimas décadas, testemunhou-se um significativo avanço do protagonismo político e profissional do Serviço Social, manifesto, particularmente, nas lutas dos profissionais pela construção de direitos sociais na esfera pública, especialmente no âmbito da Seguridade Social.

As políticas sociais, contudo, por carregarem as contradições inerentes ao capitalismo, representam formas históricas resultantes de lutas sociais e pactuações contínuas e intermináveis que nem sempre são favoráveis aos interesses da maioria da população, particularmente se considerarmos a conformação histórica da proteção social brasileira.

Foi justamente no contexto de lutas sociais para implementação da Seguridade Social brasileira que ganhou terreno a estratégia de combate direto à pobreza. Em meio a um ambiente de desresponsabilização e desoneração do Estado em relação ao enfrentamento da questão social e de fomento à filantropia empresarial e ações das organizações da sociedade civil para assumir a execução das atividades que antes eram de responsabilidade do poder público, a ampliação das ações de combate à pobreza e sua crescente centralidade na agenda das políticas sociais ocorre simultaneamente ao "desmonte da Seguridade Social" (WERNECK VIANNA, 2001).

O objetivo do artigo não é discorrer sobre o desmonte da Seguridade Social ou descrever a trajetória de formação institucional das políticas de combate à pobreza, mas apresentar uma reflexão sobre os rumos que o debate sobre política social no Brasil tomou nesse contraditório período dos anos 1990 e 2000, particularmente observando a relação do combate à pobreza com a Política Nacional de Assistência Social (PNAS, 2004).

Um primeiro aspecto que merece destaque é o esmorecimento do debate em torno dos princípios implícitos na concepção de política social presente na Constituição de 1988, que não tratava de combater a pobreza, mas de configurar "políticas destinadas a assegurar direitos e o caráter universalista dos mesmos" (WERNECK VIANNA, 2008, p. 122). A principal expressão disso é a redução das discussões relativas ao conceito de Seguridade, particularmente, no que se refere ao princípio de universalidade.

Werneck Vianna (2008) observa que o sistema de proteção social brasileiro continua universal do ponto de vista do marco legal, mas que tal concepção não conhece existência real, pois o que se verifica é uma crescente tendência de que política social é algum tipo de ação voltada para os pobres ou "excluídos" e, por isso, deve ser focalizada. Diante de tal assertiva, as controvérsias entre universal e focalizado não se resumem a escolhas que governantes fazem diante de recursos parcos e demandas cada vez maiores, nem representam apenas divergências ideológicas, são expressões de concepções teóricas distintas.

Nas duas últimas décadas, a reestruturação da noção de política social em direção aos mais pobres, cada vez mais distante da concepção de Seguridade, aconteceu vinculada a outros aspectos fundamentais: a mudança do estatuto teórico da questão social, que passa a ser cada vez mais reduzida à pobreza (IVO, 2006; MAURIEL, 2008b; UGÁ, 2008; WERNECK VIANNA, 2008, 2009), vista como ausência de capacidades; e a dimensão internacional da centralidade do combate à pobreza como estratégia de regulação dos custos do trabalho sob a dinâmica da financeirização excludente.

Isso traz sérias implicações simbólicas e práticas para a implementação da Política Nacional de Assistência Social, que, enquanto política pública, constitui-se em um caso paradigmático da mudança de concepção de política social no cenário brasileiro a partir da Constituição de 1988, haja vista que as ações assistenciais foram utilizadas historicamente como instrumento eleitoreiro e moeda de barganha populista.

\section{Pobreza e política social - um debate necessário}

O lugar cada vez mais privilegiado que a pobreza assume no debate sobre política social faz com que as formas adotadas para o enfrentamento da questão social impeçam a generalização dos direitos sociais. O problema não está só na prioridade da pobreza, enquanto categoria de análise para pensar as políticas sociais, mas na forma e no tratamento dado aos "pobres", que são renomeados por suas fragilidades, descontextualizados, des-historicizados, aparecendo no discurso tecnocrático reconstituídos por um novo tipo de vigilância moral.

A pobreza aparece distanciada dos debates estruturais e transformada num objeto técnico "em si". Essa mutação, ao mesmo tempo, discursiva e prática, isola a compreensão do pauperismo da dinâmica estrutural de produção da riqueza, fazendo com que o trabalho, nos termos ideológicos dominantes, deixe de ser o centro ordenador das políticas sociais, transformando-as em oportunidades individuais de obtenção de renda (VALLA, 2005).

Há uma hipervalorização das análises técnicas da pobreza e as razões ultrapassam a busca da eficácia na implementação dos programas. Trata-se de uma forma particular de desapropriação cultural, política e simbólica (TELLES, 2001), em que a questão social tem sido ressignificada pela ação instrumental e por meio de códigos de um "novo" economicismo "solidário" (MENEZES, 2007). Esse produtivismo de dados, de avaliações, de registros intermináveis nas e das políticas sociais desconsidera compromissos his- 
tóricos com a cidadania, especialmente no que se refere aos princípios constitucionais brasileiros.

Esse movimento não pode ser contrarrestado apenas pela multiplicação de conselhos vinculados às políticas sociais, porque as leituras instrumentais da pobreza despolitizam a questão social e a própria ação política. É um plano de fuga que nega os vínculos entre política econômica e política social, relativiza as expressões da questão social no aqui e agora e magnifica uma representação de pobreza que desterritorializa a questão social, pois a definição de pobre e da pobreza pode ser calculada por fórmulas pré-definidas e índices que se encaixam em qualquer parte do mundo.

Tais postulados não são frutos de uma cegueira involuntária, como ilustra Saramago (1995) em sua ficção. Ao contrário, possuem grande eficácia ideológica, pois conseguem deixar difusas as origens da riqueza ("lícita" ou não) e se tornam poderoso obstáculo a alianças políticas e movimentos sociais que se posicionem contra a forma dominante de apropriação de riqueza. Nesse "clima" metafórico, torna-se possível realizar a proteção dos muito ricos.

$\mathrm{O}$ que se quer ressaltar, contudo, é que se tem uma concepção teórica subjacente a tudo isso e que precisa ser desvendada e devidamente criticada. Tal perspectiva foi denominada por Werneck Vianna (2008) de "liberal revisitada", por primar por cidadãos autônomos por escolha própria, por pregar a igualdade de oportunidades para que todos possam ser efetivamente livres e por defender que o direito a que todos têm é o direito a "aprender a pescar", ou seja, o direito a um ponto de partida, a uma oportunidade $^{1}$. Nessa tendência de análise, cada um deve ter capacidade de se habilitar, e as oportunidades são criadas para que cada um possa ter um funcionamento capaz de concretizar realizações, o que permitirá medir e avaliar a potencialidade das habilidades de cada indivíduo.

$\mathrm{O}$ expoente com maior proeminência no desenvolvimento dessa perspectiva é o indiano Amartya Sen (SEN, 2001, 2000), cujas ideias conformam base para a teoria do desenvolvimento humano, propagada por organismos econômicos multilaterais como PNUD e Banco Mundial. Um dos principais aspectos do pensamento seniano ligado à política social é sua análise sobre pobreza e desigualdade.

A noção de pobreza para Sen (2001) é um desdobramento da sua discussão sobre desigualdade, que tem duas dimensões principais a serem consideradas: a desigualdade econômica (de bens, de renda, de condições materiais efetivas), que traduz uma situação externa aos indivíduos, remete à estrutura; e a desigualdade de capacidades (de potencialidades ligadas às características das pessoas), onde o foco está naquilo que as pessoas podem realizar.
Combater a desigualdade significa alcançar algum patamar de igualdade, mas qual? Sen (2000) afirma que temos que igualar as capacidades de funcionar e as vantagens individuais e não a renda.

Da mesma forma que a desigualdade, a pobreza tem duas dimensões dissociadas em sua análise: a pobreza de renda e a de capacidades. A dimensão considerada prioritária é de capacidades individuais para conduzir uma vida onde as necessidades básicas possam ser supridas.

\begin{abstract}
A dissociação entre pobreza de renda e pobreza de capacidade permite ao autor focalizar o processo de desenvolvimento no indivíduo e não nas condições estruturais, pois primeiro deve-se obter liberdade (capacidades) para depois conseguir auferir renda no mercado. Embora diferentes, pobreza de renda e de capacidades são conexas, pois devemos aumentar capacidades que conduzam a um maior poder de auferir renda, e não 'dar' renda para aumentar as capacidades (MAURIEL, 2008a, p. 102).
\end{abstract}

Ele consegue sair do foco tradicional da renda, dos bens (ter) para o que as pessoas são capazes de fazer com esses bens (ser e fazer). Ora, até bem recentemente o bem-estar das pessoas era avaliado pela quantidade de bens e serviços a que tinham acesso, o que era medido basicamente pela variável renda. Ao se concentrar nas capacidades dos indivíduos, passa a considerar características ligadas às pessoas e aquilo que conseguem realizar ou não.

As capacidades de escolha conformam liberdades substantivas que se traduzem como oportunidades reais dos indivíduos promoverem seus objetivos (achievement ou realizações). A noção de capacidades para Sen é elaborada e pressupõe um indivíduo com capacidade de se capacitar/habilitar ${ }^{2}$. Desenvolvimento, portanto, significa eliminar privações de liberdade ou aumentar as capacidades.

O exercício de liberdade individual é influenciado por condições habilitadoras (como saúde e educação básicas) que devem ser garantidas para que cada indivíduo possa se desenvolver ou habilitar-se para o exercício da cidadania.

Desenvolvimento como aumento da liberdade dos indivíduos significa expansão das capacidades para as pessoas levarem o tipo de vida que valorizam (liberdade como fim). Porém, as liberdades reais desfrutadas pelas pessoas, ou suas capacidades individuais de escolha dependem de disposições econômicas, sociais e políticas, daí a importância do papel instrumental das liberdades (liberdade como meio) (MAURIEL, 2008a, p. 100).

Portanto, combater a pobreza significa desenvolver capacidades enquanto liberdades de escolha e o 
Estado tem papel fundamental em garantir condições mínimas para esse "empoderamento".

Em prefácio redigido recentemente à publicação brasileira $^{3}$, Sen reafirma que a ampliação de benefícios sociais só pode ser garantida mediante a capacitação ou "empoderamento" das pessoas, principalmente as mais afetadas pela miséria. Desenvolver capacidades efetivas para usufruir liberdades substantivas básicas constitui condição necessária para realizar mudanças sociais. Para ele, as ações de "empoderamento" ajudam a fazer frente ao pessimismo generalizado sobre os esforços públicos, pois "o mundo precisa de esperança e de know how".

$\mathrm{Na}$ concepção de política social inspirada nessa vertente de pensamento, sistemas universais têm lugar, mas somente aqueles que propiciam a capacitação dos indivíduos para o exercício da autonomia. Por exemplo, um sistema público gratuito de educação é relevante, mas de nível fundamental; um sistema de saúde público também é aceito, mas prioritariamente voltado para a promoção da saúde. Os sistemas públicos, portanto, não se destinam aos pobres, são para todos, assim como os sistemas privados, porém, o que vai definir (em tese) é a escolha dos indivíduos com base a competição entre a oferta pública e privada (WERNECK VIANNA, 2008).

Ou seja, na concepção "liberal revisitada" a convivência entre as políticas sociais universais e as focalizadas não é só permitida, mas recomendada. Esse hibridismo é justamente o principal elemento distintivo que vai caracterizar a política social hoje: um mix entre sistemas universais básicos e formas individualizadas de proteção privada.

Essa forma predominante de conceber política social, que incorpora o combate à pobreza como estratégia central de proteção social, tem uma dimensão internacional. Mauriel (2009) observa a relação entre as políticas sociais centradas no combate à pobreza e as decisões estratégicas que vêm sendo tomadas na arena internacional, especialmente pelos Estados, considerados como principais atores das negociações que se relacionam às políticas públicas. E constata que a entrada do combate à pobreza como centro das preocupações da agenda social internacional aconteceu a partir do contexto generalizado de reformas dos sistemas de welfare desde os anos 1980 quando, tanto em países centrais como nos periféricos, as políticas públicas governamentais passaram a ser elaboradas com forte referência ao movimento da economia fora de suas fronteiras.

O papel estratégico que o conjunto de ações de combate à pobreza possui hoje para manutenção do atual padrão de acumulação via financeirização caracteriza-se pela regulação dos custos da força de trabalho no mercado mundial, por meio da regulação do comportamento econômico, político e civil dos pobres, garantindo baixo risco de sublevação social e uma forma ideologicamente palatável de inserção precária dessas massas na ordem econômico-financeira contemporânea (MAURIEL, 2009, p. 45).

Esse conjunto de questões reafirma a redefinição do padrão de proteção social brasileiro (PASTORINI; GALIZIA, 2006). As principais características que vêm sendo apontadas mostram uma transição contraditória das políticas sociais, de um projeto constitucional inclusivo e redistributivo para uma tendência à assistência mitigadora (IVO, 2004), com uma complexa clivagem que configura tipos de políticas sociais que podem ser agrupadas, segundo diferentes tipos de direitos: a) aquelas que respondem pelos direitos sociais básicos estruturados pelo Estado (Previdência básica; SUS, hospitalização e consultas; benefícios e prestações continuadas da LOAS e seguro-desemprego); b) os programas que garantem os direitos sociais previstos na Constituição, mas são passíveis de corte segundo opção dos governos (reforma agrária; Fundo de Desenvolvimento do Ensino Fundamental - FUNDEF; Merenda Escolar, entre outros projetos estruturantes); c) $\mathrm{e}$, finalmente, os programas emergenciais para enfrentamento de carências e "situações de vulnerabilidade" social de segmentos populacionais específicos (inclui-se aqui toda uma gama variadas de programas focalizados na linha de pobreza que resolvam demandas legítimas não contempladas nos dois grupos anteriores) (IVO, 2004, p. 60).

As ações de focalizadas no combate direto à pobreza possuem, geralmente, caráter transitório e sua continuidade fica à mercê das opções de governos, atendendo uma demanda difusa e não estruturada no aparelho do Estado. Esse conjunto de ações, por sua vez, se ramifica em duas grandes tendências: $\mathrm{o}$ empreendedorismo, que corresponde ao estímulo à atividade empresarial empreendedora como instrumento de inclusão social (como exemplos tem-se o Proger, Proger Jovem Empreendedor, ProJovem, Programa Nacional de Microcrédito Produtivo Orientado etc. ${ }^{4}$ ); e 
o "novo" assistencialismo condicionado, que se caracteriza pela transferência de renda com condicionalidades (a principal iniciativa é o Programa Bolsa Família ${ }^{5}$ ) (WERNECK VIANNA, 2008, p. 133-134).

Esses dois conjuntos de ações de combate à pobreza possuem uma complementaridade entre si e uma coerente relação com as outras políticas sociais, ao promover o alívio imediato da pobreza, ao reforçar o exercício de direitos sociais básicos nas áreas de saúde e educação (com a garantia das condicionalidades) e ao articular-se a programas complementares (principalmente de iniciativas municipais) para geração de renda.

A "gestão estratégica da pobreza", que supõe o fortalecimento da capacidade dos pobres para lutarem contra a pobreza como sujeitos desse processo, aposta no crescimento individual e na melhoria das condições de acesso à produção (incentivo à geração de renda), ao microcrédito e, consequentemente, à mobilidade social (por seus próprios esforços pessoais). Isso significa, sob essa concepção de política social, possibilitar a conquista da cidadania para a parcela mais "vulnerável” da população, conferindo aos pobres uma possibilidade de inserção precária, pois como não é possível construir saídas de integração estrutural via trabalho regular em função do padrão de desenvolvimento global excludente, propõe-se essa forma de acomodação.

\section{Assistência social: política de seguridade ou de combate à pobreza?}

O circuito se fecha ao observarmos a relação do combate à pobreza concebido enquanto aquisição de capacidades com a Política Nacional de Assistência Social (PNAS, 2004).

Só é possível pensar a assistência social no campo dos direitos, da universalização do acesso e da responsabilidade estatal, quando pensada em sinergia com as políticas que conformam a Seguridade Social. Logo, assistência social como política pública e enquanto direito de cidadania é parte da Seguridade Social. E enquanto componente da seguridade ela deve funcionar como uma rede de proteção impeditiva da pobreza extrema, além de procurar corrigir injustiças e prevenir situações de vulnerabilidade e riscos sociais, contribuindo para a melhoria das condições de vida e de cidadania da população pobre mediante três procedimentos: provimento público de benefícios e serviços básicos como direito de todos; inclusão no circuito de bens, serviços e direitos de segmentos sociais situados à margem desses frutos do progresso; e manutenção da inclusão supracitada e estímulo ao acesso a patamares mais elevados de vida e de cidadania, mediante o desenvolvimento de ações integradas no âmbito das políticas públicas (LOAS, 1993).
Dessa forma, ela deve funcionar para incluir grupos sociais injustamente impedidos de participar dos circuitos de produção, bens, serviços e direitos existentes na sociedade brasileira. Concebida dessa maneira, a assistência social não estaria desgarrada das demais políticas socioeconômicas, e não contribuiria para desmantelá-las ou substituí-las. Ao contrário, ela funcionaria para fortalecer as condições de eficácia das demais políticas sociais e econômicas, tendo em vista o combate integrado e intersetorial à pobreza e impedindo sua reprodução entre as novas gerações, tal como postula a lei que a regulamenta.

Tal concepção apoia-se na premissa de que, com o reconhecimento da política de assistência social como mecanismo de concretização de direitos sociais, rompe-se com a visão contratualista de proteção social, que sempre exige contrapartidas do beneficiário.

O que se verifica, contudo, é que a tardia institucionalização da política de assistência ${ }^{6}$ acontece num ambiente onde o tratamento da questão social centrado no combate à pobreza focalizada só fez aprofundar o processo de desconstrução simbólica e ideológica da Seguridade enquanto base para pensar e construir as políticas sociais, dificultando justamente o caráter intersetorial que tal política deveria ter com as demais políticas públicas.

Ademais, a noção de política social presente na PNAS difere da LOAS em aspectos fundamentais do ponto de vista da concepção de proteção social, como ilustra-se nos trechos comentados abaixo.

Tudo isso significa que a situação atual para a construção da política pública de assistência social, precisa levar em conta três vertentes de proteção social: às pessoas, às circunstâncias, e dentre elas seu núcleo de apoio primeiro, isto é, a família. A proteção social exige a capacidade de 'maior aproximação possível do cotidiano da vida das pessoas, pois é neles que riscos, vulnerabilidades se constituem' (PNAS, 2004, p.14, grifos nossos).

Sob essa perspectiva, as causas da pobreza aparecem desvinculadas dos seus determinantes estruturais, separando os indivíduos submetidos a essa condição de seus lugares no sistema produtivo priorizando o cotidiano, passando a assistência a constituir um atributo individual para aqueles que "moralmente" têm direito ou potencialidade para se capacitarem.

A nova concepção de Assistência Social como direito à proteção social, direito à Seguridade Social tem duplo efeito, um o de suprir sob dado padrão pré-definido um recebimento e outro, 'desenvolver capacidades para maior autonomia'. Neste sentido ela é aliada ao desenvolvimento humano e social e não tuteladora ou assistencialista, ou ainda tão só 
provedora de necessidades ou vulnerabilidades sociais. 'O desenvolvimento depende também de capacidade de acesso, vale dizer da redistribuição, ou melhor, distribuição dos acessos a bens e recursos, isto implica em um incremento das capacidades das famílias e dos indivíduos' (PNAS, 2004, p.14-15, grifos nossos).

A proteção social básica tem como objetivos 'prevenir situações de risco através do desenvolvimento de potencialidades e aquisições', e o fortalecimento de vínculos familiares e comunitários [...]. (PNAS, 2004, p. 34, grifos nossos).

A "nova" concepção de assistência, como a própria PNAS afirma, corrobora com os princípios e conceitos presentes na teoria do desenvolvimento humano ou desenvolvimento como liberdade de Amartya Sen, base que fundamenta os documentos dos organismos multilaterais como Banco Mundial e Programa das Nações Unidas para o Desenvolvimento (PNUD) e Organização Mundial do Comércio que coincide com o que Werneck Vianna (2008) classificou como concepção "liberal revisitada".

Para além das contradições de sentido da política de Assistência, passível de se perceber quando se compara seu próprio marco legal, ainda deve-se considerar as fragilidades no plano institucional, cujos efeitos aparecem na segmentação da exclusão ao aprofundar um conflito redistributivo de base, entre pobres e quase-pobres (IVO, 2004). A opção de calcular com precisão crescente "os mais pobres entre os pobres", sedimenta segmentos de "excluídos" da própria proteção social. Isso gera uma distorção de sentidos na relação entre os cidadãos e o Estado do ponto de vista dos direitos, criando uma nova estratificação social na base. Isso tem implicações políticas importantes, pois desloca o foco das lutas pelo acesso às riquezas socialmente produzidas, dissociando proteção e direitos sociais.

\section{Conclusões, ainda que preliminares...}

Há mais de uma década, Menezes (1998) já denunciava "a pobre análise da miséria" quando pesquisou a produção teórica das políticas de assistência pública, mostrando que a maioria das leituras sobre política social, em geral, e da assistência, em particular, estava limitada ao horizonte político-institucional, à superestrutura, o que tinha como consequência o politicismo e o reformismo institucional. E isso, afirma a autora, não se deve à falta de fundamentação teórica, mas ao tipo de teoria utilizada.

Hoje, uma perspectiva hegemônica de política social se apresenta como pressuposto, embasada por uma visão reduzida de questão social como pobreza, esta entendida como falta de dotação e de capacidades. Esse "enquadramento" do debate faz com que, novamente, retome-se, ainda que por caminhos teóricos renovados, uma concepção superdimensionada das políticas de assistência social no trato à questão social.

Um retrocesso para Werneck Vianna (2009), para quem o debate teórico atual sobre política social e suas estratégias (universais ou focalizadas) deve ter como preocupação (central e não única) a discussão dos fundamentos teóricos que tratam da conciliação entre justiça social e liberdade individual, pois essa formulação remete à percepção da questão social como desigualdade. Pois foi justamente nesse plano de reflexão que a concepção liberal conseguiu "inovar":

A inovação consiste em resgatar a possibilidade de conciliação entre justiça social e liberdade individual sem descartar a premissa liberal do primado da liberdade sobre a igualdade, ou seja, reiterando como meta a realização da individualidade (WERNECK VIANNA, 2009, p. 27).

O pensamento de Sen e os desenvolvimentos posteriores em forma normativa de recomendações de organismos multilaterais no atual contexto de relações internacionais, onde a importação de modelos externos é a meta a ser atingida, faz com que o alinhamento dos governos às premissas, consideradas vantagens competitivas no mercado global, deva ser seguido à risca como solução para construção de um padrão de proteção social compatível com o funcionamento do atual padrão de acumulação flexível.

Essa acelerada dinâmica, conduzida pelo pragmatismo, banaliza o conceito de universalização, de cidadania e de justiça social, pois os sistemas classificatórios e os critérios de permanência constituem ferramentas reais de controle dos pobres. Os resultados desses processos, além da reiteração e do aprofundamento das desigualdades, aparecem na desmobilização de atores políticos relevantes na luta por direitos.

Nessas circunstâncias não bastam discursos préformatados e estagnados, nem a repetição doutrinária de certezas ou esperanças radicais românticas e messiânicas. Impõe-se a defesa do pensamento crítico para discernir por que tipo de política social trabalha-se para universalizar e por que tipo de direitos está se lutando. Fica aqui o compromisso de resistir e partir para o embate de ideias.

\section{Referências}

GREEN, D. Da pobreza ao poder: como cidadãos ativos e estados efetivos podem mudar o mundo. Prefácio de Amartya Sen. São Paulo: Cortez; Oxford: Oxfam International, 2009. 
IVO, A. B. L. A reconversão do social. Dilemas da redistribuição no tratamento focalizado. São Paulo em Perspectiva, v.18, n. 2, p. 57-67, 2004.

- A reconversão da questão social e a retórica da pobreza nos anos 1990. In: CIMADAMORE, A.; DEAN, H.; SIQUEIRA, J. (Org.) A pobreza do Estado. Reconsiderando o papel do Estado na luta contra a pobreza global. Buenos Aires: Clacso, 2006. p. 61-85.

LOAS - Lei Orgânica de Assistência Social, 1993. Coletânea de Leis e Resoluções. Rio de Janeiro: CRESS/RJ, 2000.

MAURIEL, A. P. O. Fundamentos do combate à pobreza na contemporaneidade: Amartya Sen e a perspectiva do desenvolvimento humano. In: SERAINE, A. B. dos S.; JUNIOR, R. B. dos S.; MIYAMOTO, S. Estado, desenvolvimento e políticas públicas. Ijuí: Unijuí; Teresina: Ed. Universitária da UFPI, 2008a. p. 87-128.

. Combate à pobreza e desenvolvimento humano: impasses teóricos na construção da política social na atualidade. 351 p. Tese (Doutorado em Ciências Sociais) IFCH/Unicamp, 2008b.

. Relações internacionais, política social e combate à pobreza. Em Pauta, Rio de Janeiro: UERJ, Revan, n. 23, v. 6, p. 43-67, jul. 2009.

MENEZES, M. T. C. G. de. Em busca da teoria: políticas de assistência pública. São Paulo: Cortez, 1998.

. Economia solidária. Elementos para uma crítica marxista. Rio de Janeiro: Gramma, 2007.

PASTORINI, A.; GALIZIA, S. A redefinição do padrão de proteção social brasileiro. Praia Vermelha, Rio de Janeiro: UFRJ , n. 14 e 15, p. 72-103, prim. e seg. sem. 2006.

PNAS-Política Nacional de Assistência Social. Versão oficial. São Paulo: Cortez, 2004.

PRAHALAD, C. K. A riqueza na base da pirâmide: como erradicar a pobreza com o lucro. Porto Alegre: Bookman, 2010.

SARAMAGO, J. Ensaio sobre a cegueira. São Paulo: Companhia das Letras, 1995.

SEN, A. K. Desigualdade reexaminada. Rio de Janeiro, São Paulo: Editora Record, 2001.

Desenvolvimento como liberdade. São Paulo: Companhia das Letras, 2000.

SERAINE, A. B. dos S. O empreendedorismo no contexto de reestruturação produtiva: um novo mecanismo institucional para enfrentar o desemprego? In: JUNIOR, R. B. dos S.; MIYAMOTO, S. Estado, desenvolvimento e políticas públicas. Ijuí: Unijuí; Teresina: Ed. Universitária da UFPI, 2008. p. 271-287.

TELLES, V. da S. Pobreza e cidadania. São Paulo: Ed. 34, 2001.

UGÁ, V. D. A questão social como 'pobreza': crítica à conceituação neoliberal. 232 p. Tese (Doutorado em Ciência Política) - Instituto Universitário de Pesquisas do Rio de Janeiro (Iuperj), 2008.

VALLA, V. V. Globalização, questão social e a nova pobreza. In:___; STOTZ, E. N.; ALGEBAILE, E. B. (Org.). Para compreender a pobreza no Brasil. Rio de Janeiro: Contraponto, 2005. p. 33-52.

WERNECK VIANNA, M. L. T. As armas secretas que abateram a Seguridade Social. In: LESBAUPIN, I. (Org.). $O$ desmonte da nação. Petrópolis: Vozes, 2001. p. 91-114.

A nova política social no Brasil: uma prática acima de qualquer suspeita teórica? Praia Vermelha, Rio de Janeiro: UFRJ, n. 18, p.120-144, jan./jun. 2008.

Voz, alívio e oportunidade ou a política social de Arquimedes no Brasil. Receita infalível ou abordagem discutível? Em Pauta, Rio de Janeiro: UERJ, Revan, n. 23, v. 6, p. $17-42$, jul. 2009.

\section{Notas}

1 Werneck Vianna (2008) ilustra muito bem a diferença entre liberalismo clássico, neoliberalismo e o que está classificando como liberalismo revisitado. Pelo escopo do texto não foi possível reproduzir os principais aspectos discutidos pela autora.

2 O termo utilizado por Sen é capability (capacidade de se habilitar) que difere de capacity (capacidade).

3 Emreferênciaaobra deGreen (2009, p. xxv).

4 Seraine (2008) mostra importância atribuída a essa estratégia como forma de combate ao desemprego no contexto internacional. Menezes (2007) ressalta a relevância crescente da "economia solidária" como projeto político que, ao inscrever os pobres no setor de crédito, incorpora como faceta de seu discurso ideológico a noção de empreendedorismo. Pérola da defesa do empreendedorismo como estratégia de combate à pobreza é o livro de Prahalad (2010). O autor defende o uso do know how empresarial e tecnológico para criar esforços conjuntos entre empresas, ONGs e outros atores para criar um "capitalismo de inclusão", na busca da redução da pobreza mediante a criação de um 
mercado centrado nas necessidades dos pobres, criando uma "comunidade de consumidores ativos e desatendidos".

5 OPrograma Bolsa Família agrega, desde 2004, os programas federais de transferência de renda que passaram a proliferar no Brasil, principalmente a partir do primeiro mandato do governo de Fernando Henrique Cardoso.

6 Após dez anos de aprovação da Lei Orgânica de Assistência Social, entre 7 e 10 de dezembro de 2003, ocorreu a IV Conferência Nacional de Assistência Social, em caráter extraordinário, que finalmente indicou a construção do Sistema Único de Assistência Social. Só em outubro de 2004, o Conselho nacional de Assistência Social aprovou a Política Nacional de Assistência atualmente em vigor.

\section{Ana Paula Ornellas Mauriel}

apmauriel@yahoo.com.br

Doutora em Ciências Sociais pela UNICAMP

Professora Adjunta da Escola de Serviço Social da Universidade Federal Fluminense (UFF)

\section{UFF - Escola de Serviço Social}

Rua Prof. Marcos Waldemar de Freitas Reis

Bloco E, sala 526

Campus Universitário do Gragoatá, São Domingos

Niterói - Rio de Janeiro

CEP: 24210-201 